\title{
Making Invisible Changes Visible: Animal Examples and the Communication of Biodiversity Loss
}

\author{
By Marit Ruge Bjærke
}

\begin{abstract}
Communicating biodiversity loss and other environmental threats is never only about relating natural science data. How different environmental discourses are presented, how they intertwine, and what concepts of nature are implied, are important parts of environmental communication. The release of the 2015 Norwegian Red List for Species by the Norwegian Biodiversity Information Centre was commented on by governmental and non-governmental organizations, and was covered quite extensively in Norwegian national and local papers. In this article, I investigate the use of animals as examples in media texts on the Norwegian Red List, and the different conceptions of biodiversity loss that they activate. The examples studied in the article vary from the listing of species' names to longer narratives connected with a single species. What they have in common, however, is that the authors use them to make the general issue of the texts more real and understandable to the reader or listener. The conceptions of biodiversity, produced through animal examples in the various media, ranged from happiness and childhood magic, to a climate-changed future, and to recreational hunting. The close reading of the examples shows that both the choice of species and, more specifically, which of the species' many relationships to portray as part of the exemplary narrative, is crucial to the conceptions of biodiversity loss and of nature that are conveyed to the public. Through their way of both exceeding and reducing the general statement they are meant to illustrate, the examples bring some ideas about biodiversity loss to the foreground, but at the same time obscure others, thus providing insight into how biodiversity loss is constructed and communicated as an environmental problem.
\end{abstract}

Keywords: Biodiversity loss, climate change, endangered species, environmental communication, exemplarity, Red List, Cuculus canorus, Lagopus spp.

Bjærke, Marit Ruge: "Making Invisible Changes Visible: Animal Examples and the Communication of Biodiversity Loss", Culture Unbound, Volume 11, issue 3-4, 2019: 394-414. Published by Linköping University Electronic Press: http://www. cultureunbound.ep.liu.se 


\title{
Introduction: A Minister, a Cuckoo, and the Mediation of a Red List
}

On November 18, 2015, the Norwegian Minister of Climate and Environment, Tine Sundtoft, held a speech entitled "We need knowledge to make the right decisions" (Sundtoft 2015). The speech was held at the launching of the 2015 Norwegian Red List for Species, a list of more than 4000 Norwegian species in danger of extinction (Norwegian Biodiversity Information Centre 2018). The Minister started her speech with a question. "What is happiness?" she asked, and continued:

\begin{abstract}
It can be to feel the sun shining and hearing "from the hillside a cuckoo saying cuckoo". Knowing that spring is here. Feeling the tingling in the body from when we were children. Then we knew that if we could just steal towards - and hide under - the tree where the cuckoo sat and crowed, we could wish for something. Now, preliminary Red List numbers from the Norwegian Biodiversity Information Centre show that the cuckoo seems to be in strong decline. Possibly as a result of the climate changes. (Sundtoft 2015)
\end{abstract}

In her speech, the Minister communicated biodiversity loss and the 2015 Norwegian Red List for Species by choosing one of the species on the list, the cuckoo, and relating it to her own childhood experience. She used the cuckoo as an example, and told her story as an exemplary narrative, to show that biodiversity connects the past to the future, and culture with nature, and to draw attention to what we stand to lose.

Two of the main obstacles when attempting to communicate environmental problems, are the fact that most environmental problems emerge gradually over a long period of time, and that they necessitate action before the full effects can be seen (Adam 1998: 8-10, Doyle 2011: 4). In other words, most environmental problems are, in a sense, invisible. Simply put, biodiversity loss is made visible through a twofold process. First, it has to be 'produced' as science, most importantly through the construction of Red Lists (Braverman 2017). Red Lists are lists of species at risk of going extinct. The first Red Lists were created during the 1960s by the International Union for Conservation of Nature (IUCN), the organization that now provides the global IUCN Red List of Threatened Species (International Union for Conservation of Nature 2018). In Norway, the 2015 Norwegian Red List for Species is the third and last version of the Norwegian Red List, so far. ${ }^{1}$

Second, the results from the Red List assessment process must be communicated to the public. The use of numbers is one way of presenting the problem, giving what Ursula Heise in her book, Imagining extinctions (2016: 55), has called "a panoramic view of mass extinction". However, using examples of endangered 
species, the way the Minister of Climate and Environment does, is another way to try to get the public to relate to the problem of biodiversity loss. Literary scholar John Lyons (1989: 28) has stated that in early modern texts, examples were "a way of gesturing outside the pure discourse of the speaker/writer toward support in a commonly accepted textual or referential world". That examples gesture outside the textual discourse is not limited to early modern texts, however. Textual examples also represent a way of making contemporary environmental problems 'real' to the reader or listener.

An example can be defined as a particular instance, chosen to support a general statement, among a range of possible cases. The general statement, however, only accounts for a limited aspect of the particular instance, and this means that the example contains an excess of meaning which can be brought into the text by association (Lyons 1989: 33-34). At the same time, the particular nature of the example that was chosen also influences the general statement. Thus, examples always both exceed and reduce the issue they are meant to illustrate. In this article, I explore the use of animals as examples in the mediation of the 2015 Norwegian Red List for Species released by the Norwegian Biodiversity Information Centre (Artsdatabanken). The examples studied in the article vary from the listing of species' names to longer narratives connected with a single species. What they have in common, however, is that the authors use them to make the general issue of the texts more real and understandable to the reader or listener. While some animals from the list are used repeatedly as examples, others are used sparingly, and most of the species on the Red List are never used as examples at all. My aim in this article is to examine the different conceptions of biodiversity loss in the Norwegian public sphere. My contention is that close examinations of animals as examples and the conceptions they activate provide important insight into how biodiversity loss is constructed and communicated as an environmental problem.

\section{The child, the past and the struggle for knowledge}

Newspapers, NGOs and governmental bodies all have different roles in the media landscape. While newspapers are governed by media logics, the NGOs and governmental bodies are governed by their PR-strategies. The release of the 2015 Norwegian Red List for Species was commented on by several non-governmental organizations, and was covered quite extensively in Norwegian national and local papers. Except for the Norwegian Biodiversity Information Centre themselves, the Ministry of Climate and Environment was the only governmental body that published a press release on the day the Red List was released - and then only a written version of the speech given by their Minister. There is, however, a remarkable degree of similarity between many of the texts, as a large number of the news- 
papers cite the NGOs and draw their examples from them. By using material from both governmental and non-governmental organizations published on the day the 2015 Norwegian Red List for Species was released, and comparing it to material published in Norwegian newspapers in the following weeks, it is possible to trace the recurrence of some of the examples throughout the material, and investigate how they change along the way.

The speech made by the Norwegian Minister of Climate and Environment at the launching of the 2015 Norwegian Red List for Species starts with the question of what happiness is. The answer is the story of a cuckoo and a childhood memory. The hearing of the cuckoo is set in an idyllic scene; the sun is shining and it is springtime, and the Minister remembers the tingling in the body from when she was a child, before going on to describe how one could claim a wish from the cuckoo. The childhood memory ends quite abruptly with the information that the Red List now shows the cuckoo to be in strong decline. Only the context of the speech and this abrupt ending show that the story about the cuckoo has something to do with biodiversity loss. Although the Minister starts by asking what happiness is, the answer becomes relevant to the occasion only because it is connected with biodiversity. The story about the cuckoo and the childhood memory, then, is an example intended to show the reality of biodiversity loss: Since one kind of happiness is feeling the sun shining and hearing the cuckoo, the information from the Red List that the cuckoo is about to disappear, means that happiness is about to end.

By combining the question of happiness and the results from the Red List, the Minister evokes several assumptions about the good life as well as about what biodiversity loss is. Firstly, happiness is dependent on interactions between humans and nature. Biodiversity loss is much more than the loss of a species; it is the loss of a way of life, for humans as well as for cuckoos. The example presents biodiversity loss in a similar way to what Thom van Dooren in his book, Flight Ways, calls 'entanglements' (van Dooren 2014). Species are not separate entities, and extinctions are not specific moments in time. Rather, species should be understood as "vast intergenerational lineages, interwoven in rich patterns of co-becoming with others", and this in turn shows that the disappearance of a species will be felt in "a range of complex and drawn-out ways" (van Dooren 2014: 12). If cuckoos become extinct, one possible form of happiness and one part of the magic of childhood will also disappear.

Secondly, the good life seems to be a thing of the past. While the 'now' is represented by the decline of the cuckoo and climate change, the use of the past tense in this childhood memory shows the past as the time of real happiness, when this kind of interaction between humans and nature was possible. The Minister refers to childhood both explicitly, by describing the memory of cuckoo-related 
folklore from childhood and by using a citation from a very common Norwegian children's song about hearing the cuckoo in the forest. " "Then we knew", the Minister says. With the use of the pronoun 'we', the Minister suggests that we have all been children, searching for that cuckoo, but also that there is some secret knowledge of childhood that is lost to us.

References to childhood do not necessarily point towards the past. Both in climate change discourses and in the imaginings of a catastrophic future, the child often signifies the future and the question of what we are doing to the planet of our children (Sheldon 2016: vii, Kverndokk In press). However, in this case, the child does not evoke the future, but rather underlines the breach between a harmonious past and a disrupted present. The example evokes an association to the Christian story of the Garden of Eden and the fall of man, where humanity in a childlike state roams the beautiful garden of nature, until they make a mistake that separates them from a state of grace forever. Without the cuckoo, the possibility of having a wish granted is lost, and there is no way back to the idyll that once was.

Although the use of examples in contemporary texts and in speeches is mainly intended as a way of illustrating something or supporting an argument inductively, the story of the cuckoo can be likened to what in medieval and renaissance texts was called an exemplary tale: "a short narrative to illustrate a moral point" (Lyons 1989: 9). By making assumptions about the good life, it embodies both a general illustration of a red-listed species and a moral statement about what the good life consists of. Such a combination of being an illustration and functioning as a kind of ideal at the same time is a typical feature of examples (Eriksen et al. 2012: 9). The two different ways of using them have co-existed since antiquity and still influence how they are understood. On one hand, examples were used as illustrations to support an argument; on the other hand, they were used as ideals or models (Gelley 1995: 1). This basic ambivalence between the illustrative aspect and the ideal is retained in any example - for instance in the uniqueness that made the author of the text choose it (Eriksen et al. 2012: 9). The cuckoo is one among many species on the Norwegian Red List, and as such is just a randomly chosen representative of the other species on the list. On the other hand, the cuckoo in the Minister's speech is obviously unique. The 2015 Norwegian Red List for Species contained more than 4400 species, but the specific conception of happiness - as a relationship between humans and nature, grounded in innocence and the knowledge that magic exists - that are embedded in the exemplary tale of the Minister's example, is not provided by any of the other species on the list.

Thus, when biodiversity loss and Red Lists are presented through species examples, the choice of example also has moral implications. While the example of the cuckoo provides the listener with the expected connection to the 'reality' of biodiversity loss that is understood to be the main rhetoric function of examples, 
it contains other features, linking it with innocence, the past, and the Garden of Eden. Although intended as an illustration of the Red List, the example of the cuckoo, through its inherent excess and its ambivalent status between illustration and ideal, brings forth the general trope of a time where humans lived in harmony with nature, implying that such harmony is good, but also that it is a thing of the past.

Through its excess, the example of the cuckoo also brings forth a view of what knowledge is. "Then we knew", says the Minister. The ones who know are the children, and what they know is that the cuckoo could help them get a wish granted. The idea of knowledge, is, however, also a large part of the context the speech places the story of the cuckoo and happiness within. After finishing the example with the information that the cuckoo seems to be in strong decline, possibly as a result of climate change, the Minister continues:

This is important knowledge. We need knowledge to make the right decisions. Since the Norwegian Biodiversity Information Centre was established in 2005, you have obtained, systematized, evaluated and communicated knowledge about the diversity of nature. You have delivered important knowledge throughout the period you have existed. Knowledge that forms the basis for decisions on how to manage nature. Thank you for the job you have done. (Sundtoft 2015)

The change from sensory experiences such as 'sunshine' and 'tingling' is sudden. The "then we knew" from the first paragraph of the speech is replaced with the more distant "important knowledge". The Minister addresses the staff at the Norwegian Biodiversity Information Centre and the work they have done directly, and recites the number of species that have been evaluated, the number of species that are considered threatened, and the number of experts that have done the assessments. The knowledge she refers to here is numerical, rather than traditional. It is systematized and evaluated. Still, there is a moral tone to the speech: "We need knowledge to make the right decisions", she says. The Minister does not say what these "right decisions" are, only that the Red List will provide an "important professional basis" in the work on the government's next White Paper on nature.

To focus on the struggle for scientific knowledge is a quite common way of presenting biodiversity loss, and has been so since the production of Red Lists started (see for instance Fisher et al. 1969: 20). Such a focus is based on the expectation that lack of knowledge can lead to the wrong measures, as well as difficulties in convincing policy makers to do something about the problem of biodiversity loss. Producing Red Lists have been considered an important way of countering such a lack, and in their $50^{\text {th }}$ year anniversary publication, the international IUCN 
Red List, for instance refer to the Red List as a "gold mine of knowledge" (Vincent \& Noel 1966: Introduction, Smart et al. 2014: xxv). Ursula Heise, (2016: 76-78) has found traces of narratives of such epic struggles for scientific knowledge in species assessments from the IUCN Red List, as well as in fictional texts on biodiversity loss.

In this case, the switch from a unique example showing that nature and culture - as well as humans and other species - are entangled, to numeric knowledge seems at first to make an awkward combination. While the example presents a nostalgia for the past, and indicates that an innocent childhood is gone forever, the struggle for scientific knowledge points towards the future possibilities of science, and also seems to obscure the feeling of a connection with nature from the example. However, in parallel with the focus on science, there is a common environmental trope stating that there is an alternative knowledge, or wisdom, besides the scientific knowledge, important for making "the right decisions". This knowledge, or wisdom, is usually separated from (post-)modern societies either in time or space; it is held by, for instance, Stone Age people or by indigenous peoples (see for instance Fisher et al. 1969: 18-19, Whyte 2013, Whyte 2017). With the phrase, "Then we knew", the child in the example assumes a similar role. While the authorization of the knowledge held by indigenous peoples is often construed as a certain form of cultural authenticity and commemorates a lost cultural past (Ødemark 2015: 474), the child's knowledge is rather authorized by its psychological authenticity, its innocence. The child holds knowledge of the magic of nature, more similar to ancient wisdom than to scientific numbers. Thus, the example of the cuckoo and happiness is, in a way, also about knowledge. We need to know both what happiness is, and the scientific facts, to make the right decisions. Both the example and the scientific Red List provide knowledge that is necessary to grasp and relate to biodiversity loss.

\section{Climate reductionism or not?}

There is only one animal used as example in the Minister of Climate and Environment's speech, and only one cause for biodiversity loss is mentioned in connection with the example. This cause is climate change. Since the Minister lets one example represent the whole Red List, the reality she links to through her exemplary narrative is a reality where not only biodiversity, but also the possibility of happiness and magic, are threatened mainly by climate change. The Minister's choice of example for her speech thus produced an implicit connection between the 2015 Norwegian Red List for Species and climate change. However, other contributors to the mediation of the list made this connection more explicitly. WWF Norway was among the non-governmental environmental organizations that posted news 
articles on the 2015 Norwegian Red List for species on the same day that the list was launched, and they openly activated climate change as the overarching story of the new Red List (WWF Norway 2015). The posting from WWF Norway was entitled "New Red List for Threatened Species - 172 Species in Norway are Threatened by Climate Change". The text started with the claim that "The number of species threatened by climate change in Norway is increasing rapidly. The mountain hare, ptarmigan, walrus, puffin, arctic fox and polar bear are all in trouble due to warmer weather, shows the new Norwegian Red List for species" (WWF Norway 2015). The text uses various examples to show the ways that species can be threatened by climate change: The puffin lacks food because of climate change, the mountain hare and ptarmigans need snow as camouflage because they are white in the winter, the walrus needs ice, and the glacier buttercup is threatened by rising temperatures in the mountains. Thus, the examples form a series, underscoring various ways in which climate change may lead to biodiversity loss. WWF Norway then combines the climate change threat with a call for "the world's leaders to take the consequences of the knowledge we have, ensure a global and ambitious climate agreement in Paris and save the nature in the Arctic" (WWF Norway 2015).

Although not part of the official launching of the 2015 Norwegian Red List for Species, the strategy and examples of WWF Norway became influential in how the list was presented in Norwegian newspapers. The primary news agency in Norway, The Norwegian News Agency (Norsk Telegrambyrå, NTB), sent out several texts about the new Red List to Norwegian newspapers, and one of these texts was called "Climate Changes Threaten More Norwegian Species", and included a statement from the secretary general of WWF Norway. This was quite similar to the one in the posting from WWF Norway themselves:

- The new Red List tells about a changing nature. Near and dear species like the ptarmigan, mountain hare and cuckoo are exposed as the temperature rises, Nina Jensen, Secretary General of the environmental organization WWF Norway says. - Now the world's leaders must take the consequence of the knowledge we have and ensure a global and ambitious climate agreement in Paris, she adds. (Føli 2015)

The overarching story conveyed by these texts is that climate change is the reason that species go extinct, and that doing something about climate change is the way to prevent future extinctions. More than half of the 41 printed newspapers that published articles on the new Red List after it was released, mentioned climate change as a pressure on biodiversity, and the Secretary General of WWF Norway was quoted directly on relating the new Red List to climate change in seven of the newspaper articles. In six of these, she was also quoted on linking the Red List 
with the need for a Paris agreement. Thus, the idea that biodiversity loss is caused by climate change filtered through into Norwegian mass media.

In several recent studies, media coverage of climate change has been shown to be systematically higher than media coverage of biodiversity loss under otherwise similar circumstances (Young et al. 2014, Legagneux et al. 2018). These differences have been attributed to various aspects of the two discourses. Zaccai \& Adams (2012: 567), for instance, contend that climate change is better defined as a policy issue, and as a subject of daily concern for lay persons, that the measurement units of climate change science ( $\mathrm{CO}_{2}$ equivalents) are easier to understand; and to the fact that climate change is connected to an important strategic matter such as energy. Legagneux et al. (2018: 3), on the other hand, try to explain the discrepancy by pointing to the similarities between climate change and belief systems, the norm of balanced reporting being activated, and the fact that biodiversity loss is perceived as taking effect on a local scale, while climate change is perceived as global. They also bring up possible lag effects stemming from the fact that the IPCC (Intergovernmental Panel on Climate Change) is more than 20 years older and have more resources than the IPBES (Intergovernmental Science-Policy Platform on Biodiversity and Ecosystem Services). During recent years, when a number of studies have shown that climate change gets more media attention than biodiversity loss, several authors have argued that biodiversity loss should be embedded in a climate change discourse whenever possible, to increase public awareness and political interest in biodiversity loss as an environmental threat (Veríssimo et al. 2014, Legagneux et al. 2018). One might argue that WWF Norway follows this strategy, and that they embed the 2015 Norwegian Red List for Species in a climate change discourse to increase the publicity of biodiversity loss. As their press release and statements influenced several of the newspapers either directly or through The Norwegian News Agency, one might also claim that the strategy worked. However, such a strategy has both advantages and drawbacks when it comes to the understanding of biodiversity loss that is conveyed to the public. Presenting biodiversity loss as closely connected with climate change helps envisage biodiversity loss as a global environmental problem, but at the same time gives the impression that climate-related measures aimed towards limiting future changes in global temperature, such as the Paris-agreement, will be enough to stop it. Although climate change is one of the drivers of biodiversity loss, and climate change and biodiversity loss are both environmental problems with a global reach, the two problems are still to a large degree in need of different measures. The Norwegian Biodiversity Information Centre states that changes in land use is a pressure on more than 90 percent of the threatened species on the 2015 Norwegian Red List for Species, while climate change is a pressure on four percent of the threatened species (Norwegian Biodiversity Information Centre 2015). There is 
also a fine line between trying to boost biodiversity loss by connecting it to climate change, and using a media event on biodiversity loss as a means to talk about climate change. The 2015 Norwegian Red List for Species was launched less than two weeks before the 2015 United Nations Climate Change Conference (COP 21) in Paris, France, started. ${ }^{3}$ It is possible to understand the focus on climate change in the texts from WWF Norway and NTB as a way of using the launching of the Red List as part of the run-up to COP 21, rather than as a media event in itself.

Although media strategies are important, mediation of biodiversity loss as part of climate change may also be the result of more unintentional understandings of biodiversity loss and future climate change. Mike Hulme (2011) has introduced the concept 'climate reductionism', describing a form of analysis or prediction where the interactions between climate, environment and society that creates the future, are reduced to one determining factor, namely climate. Hulme believes that this reductionist tendency is due to an epistemological slippage from climate modelling, and that predictive sciences with statistical models and prediction power have got hegemony because they are difficult to combine with predictions from the less quantitative sciences (Hulme 2011: 249). Like climate change science, the discourse on biodiversity loss has its own numerical and technological practices produced to render the future actionable (Anderson 2010, Braverman 2017: 134), which, to a certain degree, should make it resistant to the epistemological slippage described by Hulme. Still, although Red Lists and other lists of endangered species are based on extensive scientific criteria and guidelines, these are not as 'hard science' as climate change science, and the outcomes are lists and databases, rather than models, predictions, and scenarios.

The texts from WWF Norway and The Norwegian News Agency both bear some clear signs of climate reductionism. The only pressure presented with expectations for the future and in terms of change, is climate change. This is especially visible in this passage from The Norwegian News Agency:

The proportion of the threatened species that are negatively impacted by human induced changes in land use, is stable on as much as $90 \%$. Forestry, agriculture, drainage and regrowth have large consequences for a large number of plants and animals. However, the importance of climate change is expected to increase, since the temperature will probably continue to rise. In addition, climate changes might have been underestimated, since the species are evaluated over a period of ten years - which can be too short to capture gradual changes in temperature and rainfall. (Føli 2015) 
While the impact from changes in land use is stable, climate change "is expected to increase". The possibility of climate change being underestimated is also mentioned. For the other pressures, neither their future, nor their possibility of underor overestimation are discussed. This is consistent with what Hulme claims about epistemological slippage from the fact that we have more statistical and scientifically modelled knowledge of future climate change than of future changes in land use or in pollution (Mazor et al. 2018: 1071).

However, the decision of whether to use redlisted animals as examples, and if so, of which species to use, is also an important way of reducing the future to climate change, either consciously or unconsciously. The Minister of Climate and Environment used only one example in her speech, the cuckoo. Later in her speech, she mentioned that the category "changes in land use" is "by far the largest negative impact factor for species in Norway", but this statement was neither accompanied by an exemplary narrative, nor with any mention of specific species threatened by changes in land use. As examples provide both a way of pointing outside the discourse and function as representatives of the other species on the Red List, the cuckoo threatened by climate change enforce the conception of climate change as the cause of biodiversity loss. At the same time it serves to downplay the importance of other pressures, such as changes in land use, that are not presented through examples. Like the Minister of Climate and Environment, WWF Norway states that changes in land use is the biggest threat to Norwegian species. But while the various effects of climate change are presented through examples of species suffering from these, there are no examples of species threatened by changes in land use - and thereby no exemplary narratives or indication of how changes in land use may threaten human relationships with nature. In a similar fashion, The Norwegian News Agency included no species examples in their general text on the Red List, while in the text on climate change several examples were included. Even when species such as elm and ash, which are not threatened by climate change but by new diseases, were used as examples, climate change was presented as the cause of such new diseases: "expected to grow worse, since many new species can settle in Norway when it becomes warmer" (Føli 2015). Through the examples, therefore, it is not only the future that is reduced to climate change. Environmental problem such as biodiversity loss and the transfer of new diseases are turned into effects of climate change rather than separate, but connected, problems. To let all the examples in a text point to climate change is a powerful way of defining the outside world, and as such reduce it. 


\section{A closed tale - and an open one: ptarmigans all over}

"To make an example of an object is to account for only one limited aspect of that object," John Lyons writes (1989: 34). In her speech, the Minister's exemplary tale of the cuckoo presents one relationship between the cuckoo and humans, limiting the cuckoo to its role as a granter of wishes. However, this is only effective insofar as the reader or audience does not bring in his or her own knowledge and associations. The cuckoo is connected to a large number of traditional beliefs, folk medicine, omens and magic in various cultures, that the reader or audience might be aware of, and draw into the story by association (Tillhagen 1978: 157). Although there is magic in the story of the cuckoo as a granter of wishes, the magic connected with the cuckoo in folklore is more often negative or dangerous, representing the bird as a sign of death or sorrow, or with the ability to bewitch people (Tillhagen 1978: 157-177, Kostveit 2000: 47-48). In some places, hearing the first cuckoo in spring before breakfast meant that accident and illness would strike for the rest of the year, while in other places hearing the cuckoo crow before the trees had budded meant that many unwed women would become pregnant (Kostveit 2000: 47, 34).

The way the Minister presents the cuckoo as an example also leaves out possible relationships between the cuckoo and other species. For instance, there is a close, parasitic relationship between the cuckoo and the meadow pipit (Anthus pratensis). In Norway, the majority of cuckoos lay their eggs in the nests of meadow pipits, making the meadow pipits nurture the cuckoo chicks instead of their own (Artsdatabanken 2015a). One of the reasons why the cuckoo has entered the Norwegian Red List for Species is because that relationship is changing. The meadow pipit, which is a short distance migrator, has started to migrate earlier in the spring due to higher temperatures, thus, laying its eggs earlier. The cuckoo, as a long-distance migrator, spends the winter in North Africa, and its timing is not sensitive to the rise in spring temperatures in Northern Europe. It still migrates at the same time each year, and more and more often, the meadow pipit's eggs have already hatched when the cuckoo arrives. Good for the meadow pipit, whose offspring survive, bad for the cuckoo. The meadow pipit is not on the 2015 Norwegian Red List for Species, but has been placed on both the Swedish Red List and on the global IUCN Red List, where it is categorized as near threatened (ArtDatabanken 2015, Artsdatabanken 2015b, Birdlife International 2018). As such, the cuckoo and the meadow pipit are both in decline. However, of the two, only the cuckoo can be used as an example of the 2015 Norwegian Red List for Species and Norwegian biodiversity loss. Placing a species on a Red List is in itself an action that influences existing relationships between humans and other species, and produces new ones. However, the cuckoo example involves changing human interpretations of the relationships between birds as well. Implicitly, the Minister of Climate and 
Environment needs the meadow pipit to host cuckoo eggs in its nest to uphold the magic of her childhood. Thus, to a reader or audience knowing something about the Red List status of meadow pipits in other countries, the Minister's example might instead serve as a reminder of the fact that national Red Lists, although produced as scientifically and objectively as possible, have limitations in scale, and also consequences for the species that are not included.

Despite the number of possible relationships between humans and animals, animals and animals, and humans and climate change that the cuckoo invites, very few, other than the Minister of Climate and Environment, used it as an example when writing about the 2015 Norwegian Red List for Species. The Secretary General of WWF Norway mentioned it in a series with ptarmigan and mountain hare as examples of species threatened by climate change, and this series was repeated in one local newspaper, but otherwise there was no mention of the cuckoo. Instead, the most commonly used examples from the 2015 Norwegian Red List for Species were ptarmigans (Lagopus muta and Lagopus lagopus), which are mentioned in 20 of the 42 newspaper articles, lynx (Lynx lynx) which is mentioned in twelve of the articles, and mountain hare (Lepus timidus) which is mentioned in ten. The Norwegian Red List was also, in several cases, presented only through numbers. Seven of the newspapers used no examples of species at all. This was also the case in the press release from the Norwegian Biodiversity Information Centre, which presented the 2015 Norwegian Red List for Species through more than 60 different numbers and percentages, but mentioned no specific animal or plant, nor any specific measures. ${ }^{4}$

The exemplary narratives, of which the ptarmigans are part, vary from newspaper to newspaper. In some articles, ptarmigans are a part of the longer series of red-listed species. This is the case in the texts from WWF Norway and The Norwegian News Agency, where the series points to climate change and the importance of a global agreement. It is also the case in a release from another Norwegian NGO, Friends of the Earth Norway (Naturvernforbundet). Their text, entitled "Climate and Changes in Land Use in Deadly Interaction" contains a large number of examples of animals from the Norwegian Red List:

Well known bird species such as the willow ptarmigan and rock ptarmigan, the bluethroat, yellowhammer, common house martin, and eider duck are now on the 2015 Red List. Species such as the northern lapwing, common guillemot and puffin are retaining their status as endangered, while, for example, the hen harrier has had its status reduced to endangered. (Ødegaard 2015) 
Here, the ptarmigans are part of a group of species that are new to the list, indicating that the problem of biodiversity loss is increasing. Friends of the Earth Norway were cited in eleven newspaper articles. Three of these articles were based closely on the text from their web site. These articles were easily recognizable on their long list of bird examples, mentioning ptarmigans, bluethroat, yellowhammer, common house martin, eider duck and so on (Trønder-Avisa 2015, Theodorsen 2015, Haug 2015). Eight articles used the lynx as example, and presented the Red List through a short interview with a representative from Friends of the Earth Norway stating that the hunting of red-listed species must stop (see for instance Romsbotn 2015).

In the 2015 Norwegian Red List for Species, three reasons for the decline of the two Norwegian ptarmigan species, willow ptarmigan and rock ptarmigan, are listed: climatic changes, predators and hunting (Artsdatabanken 2015c, 2015d). Articles where ptarmigans are presented as the single example from the 2015 Norwegian Red List for Species, mostly combine the presentation of the list with discussions on recreational hunting of ptarmigans and management consequences of red-listing the two ptarmigan species (see for instance Dokka 2015, Hallingdølen 2015, Sandholm 2015, Severinsen 2015, Sortlandsavisa 2015). This is not surprising considering that recreational hunting of ptarmigans is widespread in Norway. During the 2016/2017 hunting season, 46000 persons hunted ptarmigans in Norway, while 28700 persons reported felling one or more ptarmigans (Steinset \& Rundtom 2017).

In one article, entitled "Redlisted and huntable (Rødlista og jaktbar)", in the local paper Troms Folkeblad, a representative from Statskog, the state enterprise responsible for managing state forests and mountain areas, is interviewed (Dokka 2015). He emphasises that climate change and predators are the real problems for the ptarmigans, not recreational hunting. "[W]e expect that climate is one of the main causes", the representative says. "It is very easy to say that these [the decline in ptarmigan populations] are side effects you get because of hunting. But it is dangerous to blame hunting for this decline". On the surface, this article uses the ptarmigan as an example to promote a story of biodiversity loss and climate change similar to the one in the texts from WWF Norway and The Norwegian News Agency. However, although presented through the same species example, the relationship between humans and nature in the examples are very different. In the texts from WWF Norway and The Norwegian News Agency, the ptarmigans are signs of climate change, vulnerable, and therefore our responsibility to protect. In Troms Folkeblad, the ptarmigans are prey and the humans are hunters. Here, ptarmigans represent a service provided by nature, a service that is now in danger of being discontinued. Thus, the global scopes of biodiversity loss and climate change seem distant, almost irrelevant in this article, compared to the possible 
effects on upcoming ptarmigan hunts. The placing of the ptarmigans on the 2015 Norwegian Red List for Species indicate a danger of extinction for the ptarmigans, but it is first and foremost perceived as a threat to Norwegian hunting traditions.

Troms Folkeblad is a local newspaper, and the local scope is expressed in a discussion of the difference between local abundance of ptarmigans and the national scope of the Norwegian Red List. The temporal perspectives are also short term. The article does not concern itself with a distant future, where ptarmigans may be extinct, but rather focuses on upcoming seasons.

Presenting something as local, and as part of local practices, increases people's understanding of biodiversity loss as being close to them and their daily lives. References to traditional hunting practices, folklore and childhood experiences are ways of activating feelings and interest. Thus, it is significant that the three species most commonly used as examples in the newspaper articles on the 2015 Norwegian Red List for Species were species that are subjected to hunting in Norway; ptarmigans and mountain hares through recreational hunting, and the lynx because it kills livestock and domestic reindeer, and are therefore species that many Norwegians relate to in one way or another. At the same time, these practices and experiences are always local in their scope, and as such undermine the understanding of biodiversity loss as part of a global problem. Ptarmigan populations are not even considered on the national level in most of the local newspapers, but as local populations calling for local management strategies. As ptarmigans are only categorized as 'near threatened' on the Red List, and are still a common sight in many parts of Norway, it might be difficult to unite them with the conception of a species on the verge of extinction.

Since the ptarmigans are particular instances of both global climate change and local hunting traditions, and are able to function as examples of both, the articles in these local papers have to juggle and combine the various ideas and spatial scales of biodiversity loss, climate change, hunting traditions, and nature management. As an example, the ptarmigan becomes a focal point for several different conceptions of nature, producing slightly differing stories in different newspapers. As Legagneux et al. (2018) have argued, disagreement and the norm of balanced reporting has contributed to the media coverage of climate change. Therefore, presenting biodiversity loss through examples of species that matter enough to people that they are willing to disagree about them, seems to be a good idea if one wants to be read - whether one is an environmental NGO or a local newspaper.

The ptarmigans are used as examples of global climate change, of birds, of hunting traditions, and of the necessity of local management. They are discussed in web postings by environmental NGOs and presented in national and local newspapers, and although the examples change and turn the biodiversity discourse along the way, they, at least, evoke interest in the 2015 Norwegian Red List 
for Species. The cuckoo, on the other hand, is not widespread in the material. One important explanation is probably that the cuckoo is of little or no economic value, and that the threats to the species are relatively unspecific. There are no controversial political measures that should or should not be taken, except for climate change measures, which in Norway are largely decided on through cross-party settlements (Båtstrand 2014). Although the cuckoo is connected to human life through various magical practices, these practices do not have direct political implications, neither do they have a large place in the daily lives of most Norwegian newspaper-readers.

Although Zaccai \& Adams (2012) and Legagneux et al. (2018) studied differences in media coverage between climate change and biodiversity, many of the differences they point out between the two discourses can also be seen among the examples in this study - where some species from the Red List get a lot more media coverage than others. The species that are reproduced as examples in various mass media are species that are of daily concern, that are connected to political matters, and that are subject to controversial measures with economic consequences or to public skepticism. However, the fact that examples contain excess information that will always, to a certain degree, be in conflict with the general rule they are supposed to support, presents a danger to the author who wants to make a certain point without being drawn into any controversy. The Minister of Climate and Environment might have chosen the cuckoo as an example because it is uncontroversial, and as such is less likely to be used in new and unexpected ways. The consequence, however, was that her example was not used by anyone else.

\section{Making biodiversity loss visible}

This close reading of some of the examples of animals that were used in connection with the 2015 Norwegian Red List for Species shows that both the choice of species and, more specifically, which of the species' many relationships to portray as part of the exemplary narrative, is crucial to the conceptions of biodiversity loss and of nature that are conveyed to the public. The Minister of Climate and Environment's example of the cuckoo portrays biodiversity loss through breaches and bonds between past and present, childhood and adulthood, and between humans and nature. While Doyle (2011:3) has criticized the use of nature in the mediation of climate change, for making climate change an environmental issue as opposed to an issue concerning humans and culture, and thus distant and difficult to engage with, this example shows that animal examples can just as well highlight the cultural consequences of an environmental problem as the natural consequences.

Through their way of both exceeding and reducing the general statement they are meant to illustrate, the examples do not only make biodiversity loss visible. 
While bringing some ideas about biodiversity loss to the foreground, they at the same time obscure others. The Minister's example conveys the notion of a lost paradise, but mostly ignores the future. It also makes biodiversity loss seem national or local. The story of springtime and cuckoo folklore is limited both temporally and geographically. The exemplary tales used by WWF Norway and The Norwegian News Agency, on the other hand, are global and political in scope, turning biodiversity loss into global climate change, with the Paris Agreement as the solution to the problem. They point toward biodiversity loss as a future effect of climate change. However, their examples hide present pressures on biodiversity, such as changes in land use, and fail to activate specific relationships between humans and endangered species, or show the direct effects of biodiversity loss on human practices. The large number of newspapers choosing exemplary narratives that connected biodiversity loss with hunting stressed the short term and local effects of the Red List on hunting management, related biodiversity loss closely to human practices, and presented nature in a resource perspective. The local and short term perspective of the exemplary tales, however, obscured the global aspects and longer temporalities that are usually present in the idea of a massive biodiversity loss, as well as a less anthropocentric view of nature.

The Minister of Climate and Environment and her cuckoo did not seem to play any significant role in the way biodiversity loss was presented in Norwegian mass media. The environmental NGOs, however, played a very important role in providing both example species and exemplary narratives for the journalists to use. The newspapers' reproduction of animal examples from the environmental organizations highlights a certain degree of 'churnalism' in the Norwegian public. However, although the most commonly used examples of red-listed species in the newspaper articles were ptarmigans - an example that was used by the WWF Norway as an example of a species threatened by climate change - the ptarmigans did not stay the same throughout the material. Ptarmigans were used as examples of both newcomers, hunted species, and bad management, and as such they rather offered the excess necessary for the authors of newspapers articles to create what they considered the most relevant exemplary narratives, producing their own local stories and turning the biodiversity discourse in different directions - often incorporating several conceptions of biodiversity into a single newspaper article: From dear and vulnerable species that have to be protected, to biodiversity as a resource for human harvesting, and from global climate change to local management.

The case of the 2015 Norwegian Red List for Species shows that examples bring other types of knowledge into the discourse on biodiversity loss, than the numerical knowledge present in the Red List itself. In the Minister of Climate and Environment's speech, the need for knowledge was stated explicitly, and although 
the focus on knowledge in the speech was probably meant as a reference to the work that had been done in compiling the Red List, and the large number of species that had been evaluated, it still highlighted the fact that her example of the cuckoo produced another kind of knowledge necessary for biodiversity loss to be made visible - a knowledge that is not possible to provide through numbers. It is probably correct that climate change is better defined as a policy issue than biodiversity loss, and as such is easier to communicate. Still, there seem to be numerous possibilities of communicating biodiversity loss through examples in ways that makes the problem real and relatable to people. For instance, by using species examples to combine the global and the local, wisdom and knowledge, nostalgia for the past, and hope for the future. The essential point is just choosing the right example.

Marit Ruge Bjærke is a postdoctoral research fellow in Cultural Studies at the Department of Archaeology, History, Cultural Studies and Religion, University of Bergen. Her research interests lie within the environmental humanities, with a focus on biodiversity loss and climate change. Bjærke is currently part of the research project 'The Future is Now: Temporality and exemplarity in climate change discourses. E-mail: marit.r.bjerke@uib.no

\section{Acknowledgements}

I acknowledge support from the Research Council of Norway to The Future is Now - Temporality and exemplarity in climate change discourses, project number 268094. I would like to thank Senior Advisor Snorre Henriksen at the Norwegian Biodiversity Information Centre for valuable information on the launching of the 2015 Norwegian Red List for Species. I would also like to thank Anne Eriksen, Kyrre Kverndokk, Henrik H. Svensen, John Ødemark, Lone Ree Milkær, Camilla Asplund Ingemark, Diane Goldstein, and Hall Bjørnstad for stimulating discussions about climate change exemplarity.

\section{Notes}

${ }^{1}$ The first IUCN Red Lists were published in 1964. The first Norwegian Red List based on IUCN criteria was published in 2006. However, Norwegian Red Lists based on other sets of criteria than those of IUCN have existed since 1984. See Norwegian Environment Agency, Truede arter [Threatened species]: http://www.miljostatus.no/ Tema/Naturmangfold/Arter/Truede-arter/ (accessed 16/2/2018).

${ }^{2}$ The citation "from the hillside a cuckoo saying cuckoo" is from the Norwegian children's song "I Went for a Walk on the Trail", where the first verse goes like this: "I went for a walk on the trail, seeking the calm of the forest. Then I heard from the hillside, 


\section{Culture Unbound}

Journal of Current Cultural Research

a cuckoo saying cuckoo. Cuckoo, cuckoo, cuckocurucuckoo. Cuckoo, cuckoo, cuckocurucuckoo".

${ }^{3}$ COP 21 lasted from 30 November to 12 December 2015 and resulted in the Paris Agreement.

${ }^{4}$ Based on a copy of the press release provided by senior advisor Snorre Henriksen from The Norwegian Biodiversity Information Centre (personal communication September 2017). The organization's web site was restructured in 2016, and the original press release is no longer accessible from artsdatabanken.no.

\section{References}

Adam, Barbara (1998): Timescapes of Modernity: the Environment and Invisible Hazards, London, UK: Routledge.

Anderson, Ben (2010): "Preemption, Precaution, Preparedness: Anticipatory Action and Future Geographies," Progress in human geography, 34:6, 777-798.

ArtDatabanken (2015): "Anthus pratensis Ängspiplärka," ArtFakta ArtDatabanken $S L U$ : https://artfakta.artdatabanken.se/taxon/102983 (accessed: 11/3/2019)

Artsdatabanken (2015a): "Cuculus canorus Linnaeus, 1758," Norsk Rødliste for arter: https://artsdatabanken.no/Rodliste2015/rodliste2015/Norge/4040 (accessed: $15 / 2 / 2019)$

Artsdatabanken (2015b): “Anthus pratensis (Linnaeus, 1758)," Norsk Rødliste for arter: https://artsdatabanken.no/Rodliste2015/rodliste2015/Norge/4322 (accessed $11 / 3 / 2019)$

Artsdatabanken (2015c): “Lagopus muta (Montin, 1781)," Norsk Rødliste for arter: https://artsdatabanken.no/Rodliste2015/rodliste2015/Norge/4070 (accessed $25 / 2 / 2019)$

Artsdatabanken (2015d): “Lagopus lagopus (Linnaeus, 1758)," Norsk Rødliste for arter: https://artsdatabanken.no/Rodliste2015/rodliste2015/Norge/4066 (accessed $25 / 2 / 2019$ )

BirdLife International 2018: "Anthus pratensis," The IUCN Red List of Threatened Species 2018: http://dx.doi.org/10.2305/IUCN.UK.2018-2.RLTS. T22718556A131986875.en (accessed 11/3/2019).

Braverman, Irus (2017): "Anticipating Endangerment: The Biopolitics of Threatened Species Lists," Biosocieties, 12:1, 132-157.

Båtstrand, Sondre (2014): "Giving Content to New Politics: From Broad Hypothesis to Empirical Analysis Using Norwegian Manifesto Data on Climate Change," Party Politics, 20:6, 930-939.

Dokka, Morten (2015): "Rødlista og jaktbar [Redlisted and Huntable]," Troms Folkeblad, 23 November 2015.

Doyle, Julie (2011): Mediating Climate Change, Farnham: Ashgate.

Eriksen, Anne, Ellen Krefting \& Anne Beate Rønning (eds) (2012): Eksempelets makt: Kjønn, representasjon og autoritet fra antikken til i dag [The Power of Example: Gender, Representation, and Authority from Antiquity to Today], Oslo: Scandinavian Academic Press.

Fisher, James, Noel Simon \& Jack Vincent (1969). The Red Book: Wildlife in danger. London: Collins.

Føli, Are (2015): "Klimaendringene truer flere norske arter [Climate Changes Threaten more Norwegian Species]," Norsk telegrambyrå (NTB), 18 November 2015.

Gelley, Alexander (ed.) (1995): Unruly Examples: On the Rhetoric of Exemplarity, Stanford, CA: Stanford University Press.

Hallingdølen (2015): "Nær truede ryper [Near Threatened Ptarmigans]," Halling- 


\section{Culture Unbound}

Journal of Current Cultural Research

dølen, 28 November 2015.

Haug, Isabell (2015): "Rødlista 2015: Rypa er utrydningstruet [2015 Red List: the Ptarmigan is Threatened by Extinction]," Framtid $i$ Nord, 19 November 2015.

Heise, Ursula (2008): Sense of Place and Sense of Planet: the Environmental Imagination of the Global, Oxford: Oxford University Press.

Heise, Ursula (2016): Imagining Extinctions: the Cultural Meanings of Endangered Species, Chicago and London: The University of Chicago Press.

Hulme, Mike (2011): "Reducing the Future to Climate. A Story of Climate Determinism and Reductionism," Osiris, 26:1, 245-266.

International Union for Conservation of Nature (IUCN) (2019): The IUCN Red List of threatened species: http://www.iucnredlist.org/ (accessed 12/11/2019).

International Union for the Protection of Nature (1954): Les Fossiles de Demain: Treize Mammifères Menacé d'Extinction, Brussels: IUPN.

Kostveit, Åsta Østmoe (2000): Fuglen i folkekulturen [The Bird in Vernacular Culture], Oslo: Landbruksforlaget.

Kverndokk, Kyrre (In press): “Talking about Your Generation: 'Our Children' as a Trope in Climate Change Discourse," Ethnologia Europaea.

Legagneux, Pierre, Nicolas Casajus, Kevin Cazelles, Clément Chevallier, Marion Chevrinais, Lorelei Guéry, Claire Jacquet, Mikael Jaffré, Marie-José Naud, Fanny Noisette, Pascale Ropars, Steve Vissault, Philippe Archambault, Joel Bêty, Dominique Berteaux \& Dominique Gravel (2018): "Our House Is Burning: Discrepancy in Climate Change vs. Biodiversity Coverage in the Media as Compared to Scientific Literature," Frontiers in Ecology and Evolution 5, 1-6.

Lyons, John D. (1989): Exemplum: the Rhetoric of Example in Early Modern France and Italy, Princeton, NJ: Princeton University Press.

Mazor, Tessa, Christopher Doropoulos, Florian Schwarzmueller, Daniel W. Gladish, Nagalingam Kumaran, Katharina Merkel, Moreno Di Marco \& Vesna Gagic (2018): "Global Mismatch of Policy and Research on Drivers of Biodiversity Loss," Nature ecology \& evolution, 2:7, 1071-1074.

Norwegian Biodiversity Information Centre (2018): Norwegian Red List for Species: https://www.biodiversity.no/Pages/135380/Norwegian_Red_List_for_Species (accessed 16/2/2019).

Romsbotn, Brit (2015): "Står i fare for å bli utrydda [In Danger of Becoming Extinct]," Joerbladet, 20 November 2015.

Sandholm, Jarl Gunnar (2015): "Rypa på rødlista [The Ptarmigan on the Red List]," Helgelendingen, 19 November 2015.

Severinsen, Jan Eskil (2015): "Varsellys for rypa [Warning Light for the Ptarmigan]," Avisa Nordland, 19 November 2015.

Sheldon, Rebekah (2016): The Child to Come: Life after the Human Catastrophe, Minneapolis, London: University of Minnesota Press.

Smart, Jane, Craig Hilton-Taylor \& Russell A. Mittermeier (2014): The IUCN Red List: 50 Years of Conservation, Washington D.C.: Cemex and Earth in Focus.

Sortlandsavisa (2015): "Nå er rypa truet [Now the Ptarmigan is Threatened]," Sortlandsavisa, 19 November 2015.

Steinset, Trond A. \& Terje Olav Rundtom (2017): "Færre ryper i sikte [Fewer Ptarmigans in Sight]," Statistics Norway, 7 September 2017: https://www.ssb.no/ jord-skog-jakt-og-fiskeri/artikler-og-publikasjoner/faerre-ryper-i-sikte (accessed $25 / 2 / 2019)$

Sundtoft, Tine (2015): "Vi trenger kunnskap for å ta riktige beslutninger [We Need Knowledge to Make the Right Decisions]," Ministry of Climate and Environment, 18 November 2015: https://www.regjeringen.no/no/aktuelt/artsdatabanken/ id2461954/ (accessed 06/03/2019).

Theodorsen, Siri W. (2015): "Nye arter trues nå av utryddelse [New Species Now 


\section{Culture Unbound}

Journal of Current Cultural Research

Threatened by Extinction]," Fosna-Folket, 19 November 2015.

Tillhagen, Carl-Herman (1978): Fåglarna i folktron [The Birds in Folklore], Stockholm: LTs förlag.

Trønder-Avisa (2015): "Rype og gaupe på rødlista [Ptarmigan and Lynx on the Red List]," Trønder-Avisa, 19 November 2015.

van Dooren, Thom (2014): Flight Ways: Life and Loss at the Edge of Extinction, New York: Columbia University Press.

Veríssimo, Diogo, Douglas C. MacMillan, Robert J. Smith, Jennifer Crees \& Zoe G. Davies (2014): "Has Climate Change Taken Prominence over Biodiversity Conservation?" BioScience, 64:7, 625-629.

Vincent, Jack \& Simon Noel (1966): Red data book. Volume 2. Aves, Morges, Switzerland: IUCN.

Whyte, Kyle Powys (2013): “On the Role of Traditional Ecological Knowledge as a Collaborative Concept: a Philosophical Study,” Ecological Processes, 2:7.

Whyte, Kyle (2017): "Indigenous Climate Change Studies: Indigenizing Futures, Decolonizing the Anthropocene," English Language Notes, 55:1-2, 153-162.

WWF Norway (2015): "Ny rødliste for truede arter - 172 arter i Norge trues av klimaendringer [New Red List for Threatened Species - 172 Species in Norway are Threatened by Climate Change]," WWF Norway, 18 November 2015.

Young, Juliette C., Kerry A. Waylen, Simo Sarkki, Steve Albon, Ian Bainbridge, Estelle Balian, James Davidson, David Edwards, Roddy Fairley, Ceri Margerison, Davy McCracken, Roger Owen, Christopher P. Quine, Charles Stewart-Roper, Des Thompson, Rob Tinch, Sybille Van den Hove \& Allan Watt (2014): "Improving the Science-Policy Dialogue to Meet the Challenges of Biodiversity Conservation: Having Conversations Rather than Talking at One-Another," Biodiversity and Conservation, 23:2, 387-404.

Zaccai, Edwin \& William Adams (2012): "How Far are Biodiversity Loss and Climate Change Similar as Policy Issues?" Environment, Development and Sustainability, 14:4, 557-571.

Ødegaard, Martin (2015): "Klima og arealinngrep i dødelig samspill [Climate and Changes in Land Use in Deadly Interaction]," Friends of the Earth Norway, 18 November 2015: https://naturvernforbundet.no/naturvern/vern av arter/klima-og-arealinngrep-i-dodelig-samspill-article34363-152.html (accessed 29/8/2017).

Ødemark, John (2015): "Avatar in the Amazon - Narratives of Cultural Conversion and Environmental Salvation between Cultural Theory and Popular Culture," Culture Unbound: Journal of Current Cultural Research, 7:3, 455-478. 